\title{
On Coordinating Knowledge Investment in the Cooperative Product Development in the Emerging Industry's Platform Innovation Ecosystem
}

\author{
Peng Ziwei ${ }^{1, a}$, Wu Shaobo ${ }^{2, b}$ \\ ${ }^{1}$ Business School of China West Normal University, Nanchong, China \\ ${ }^{2}$ Strategic Planning College, Chongqing Technology and Business University, Chongqing, China \\ apengzw1996@126.com, buusbo123@126.com
}

\begin{abstract}
Keywords: platform innovation ecosystem, cooperative product development, knowledge investment.

Abstract. This essay studies the knowledge investment coordinating mechanism of the core enterprise, which plays both the role of the platform innovation ecosystem manager and the role of knowledge investment in the cooperative product development in the platform innovation ecosystem. The study shows that the profit distributed to the core enterprise and the agent enterprises of the platform innovation ecosystem is positively correlated with the impact weight of their knowledge investment on the knowledge production value, i.e. the higher the impact weight is, the more profit they may gain, that the larger the number of the agent enterprises in the platform innovation ecosystem is, the higher level of knowledge investment effort the core enterprise will make, the larger the core enterprise's total gain will be, and that the higher the higher the knowledge coordination degree between the core enterprise and the agent enterprises is, the larger the core enterprise's total gain will be.
\end{abstract}

\section{Introduction}

The emerging industries refer to the new industries that emerge along with the invention and application of the new technologies. The technologies of the emerging industries are generally in its infancy but the emerging industries are prospective. In September of 2010, the State Council put seven industries, i.e. the life science industry, the biomedicine industry, new energy industry, new material industry, geological survey industry, the space and marine development industry, and the information network, into China's strategic emerging industries, and defined them as the pillar industries of national economy in China. The development of the emerging industries is the need of the transformation of the economic growth mode in China.

Along with the increasingly furious market competition, the technology innovation based on innovation platform is becoming more and more important for the emerging industries, such as personal computer, computer operating system and internet industry. In order to meet diverse needs, the platform owner often takes the strategy of open platform technology interface, and encourages outside innovation organizations ( such as enterprises, universities and institutes) to carry out the innovation of the complementary components on the product platform. The technology platform and the outside complementary components will jointly provide the consumers a complete set of product or service solution program (Gawer and Cusumano,2008). For example, for accelerate the speed of product innovation, IBM only focused on the development of platform technology (including hardware and middleware), and let the outside innovation organizations to develop the application software through opening the platform technology interface. The suppliers of the hardware, middleware and application software made joint efforts to form a complete set of solutions and formed a platform innovation ecosystem. Besides, Microsoft, SAP and Intel also took the similar strategy of platform innovation ecosystem to increase value creation for the consumers. Therefore, the platform innovation ecosystem is a system in which the core innovation enterprise open its technology innovation platform interface, and the enterprises, universities, institutes, suppliers, distributors, users and even competitors, who develop complementary product or component technology, form a dependant partnership. In the platform innovation ecosystem the innovation organizations will form a relationship 
that is similar to the population ecological relation in nature, they form a relationship of coexistence, symbiosis and parasitism, and jointly create value for the consumers.

In the course of the cooperative innovation of the platform innovation ecosystem, may factors, such as the knowledge flow across the boundaries of organizations, the different goals or objectives of organizations, knowledge properties, and opportunistic behaviors, may result in conflicts. The conflicts between the partners may obstruct the knowledge share and communication between the system members. Baldwin and Clark(2000), Schilling(2000) studied the engineering design, platform structure and modularized innovation methods of platform innovation ecosystem. Suarez(2004), Murmann and Frenken(2006) studied the evolution of platform technologies and the technical advantage of platform innovation. Perrons(2009) studied the platform enterprises' weighing process of trust mechanism and control mechanism to maintain their leading position in the platform innovation ecosystem. Adner and Kapoor's (2010) empirical study on the the world's semiconductor equipment industry from the year of 1962 to the year of 2005 showed that the outside challenges that influence the core enterprise's innovation performance not only relies on its scale, but also relies on its relative ecological position. Nambisan and Baron(2012) studied the main functions of the core enterprise, the standards of choosing partners and the construction of cooperation rules. Ceccagnoli eta(2012) studied the auxiliary enterprises' motives to join the platform innovation ecosystem, and found that the auxiliary enterprises aim to enter the current markets quickly, to obtain the advantages of the corresponding brands and reputation, and to obtain the chance to learn technical knowledge and realize the IPO, etc. Scholten et al(2012) studied the control mechanism of the platform innovation ecosystem. Zhang Lifei(2009)studied the operation mechanism of the hi-tech enterprises' innovation ecosystem. Zhang Yunshen studied the risk formation mechanism of the hi-tech enterprises' innovation ecosystem. Up to now there is no essay that studies the effect of the core enterprise' two roles (the role of manager and the role of knowledge investor in the course of cooperative product development) on the knowledge input coordination.

\section{Basic model hypothesis}

We suppose that the platform innovation ecosystem consist of one core enterprise and $\mathrm{k}$ agent enterprises, which may be upstream enterprises, downstream enterprises, universities or institutes. We suppose that the $\mathrm{k}$ agent enterprises are completely alike, that there is no competition relationship between them, and that these enterprises are risk-neutral. Each agent enterprise will work together with the core enterprise to carry out cooperative product development and knowledge creation. In the platform innovation ecosystem the core plays two roles, the knowledge production manager of the whole system and the knowledge investor. The letter B is used for the role of knowledge production manager and the letter $\mathrm{C}$ is used for knowledge investors. $\mathrm{A} 1, \mathrm{~A} 2, \ldots, \mathrm{Ai}, \ldots, \mathrm{Ak}$ are used for the $\mathrm{k}$ agent enterprises.

The other parameters of the knowledge production of the platform innovation ecosystem are as follows:

$\mathrm{R}$ : the total return from the cooperative product development of the whole platform innovation ecosystem.

VB: the expected return of the core enterprise $\mathrm{B}$ as the knowledge production manager.

$\gamma$ : the cost of the core enterprise $B$ as the knowledge production manager.

VC: the expected return of the core enterprise $\mathrm{C}$ as the knowledge investor.

$V_{A_{i}}$ : the expected return of No.i agent enterprise from the knowledge production.

$e_{C}$ : the knowledge input effort degree of the core enterprise as the knowledge investor $\mathrm{C}$.

$e_{A_{i}}$ : the knowledge input effort degree of the No.i agent enterprise.

$m_{B}$ : the Core enterprise's profit distribution coefficient of the total return $\mathrm{R}$ as the manager. 
$m_{C}$ : the core enterprise's profit distribution coefficient of the total return $\mathrm{R}$ as the knowledge investor.

$m_{A_{i}}$ : No.i agent enterprise's profit distribution coefficient of the total return. $m_{B}+m_{C}+k m_{A_{i}}=1$.

$l$ : cost coefficient of knowledge investment effort. The cost coefficients of the core enterprises and the agent enterprises are relatively $\frac{1}{2} l e_{C}{ }^{2}$ and $\frac{1}{2} l e_{A_{i}}{ }^{2}$.

\section{Establishment and analysis of the models}

We suppose $R_{i}$ is the knowledge production function of the core enterprise C and the No.i agent' investment effort. The function is a Douglas production function, in which $a$ and $b$ is the influence weight of their investment effort on knowledge production, and $a$ plus $b$ is equal to one $(0<a, b<1)$. The knowledge production function is

$$
R_{i}=q e_{C}^{a} e_{A_{i}}^{b}
$$

In Eq. 1, $q$ is a constant, which is greater than zero, and is the knowledge cooperation coefficient of the core enterprise and the agent enterprises.

Therefore, the return of the knowledge production of the whole platform innovation ecosystem is:

$$
R=k q e_{C}{ }^{a} e_{A_{i}}^{b}
$$

Then, the expected returns of the core enterprise as the knowledge production manager $\mathrm{B}$ and the knowledge investor $\mathrm{C}$ are relatively:

$$
\begin{aligned}
& V_{B}=\left(1-m_{C}-k m_{A_{i}}\right) k q e_{C}{ }^{a} e_{A_{i}}{ }^{b}-g \\
& V_{C}=m_{C} k q e_{C}{ }^{a} e_{A_{i}}{ }^{b}-\frac{1}{2} l e_{C}{ }^{2}
\end{aligned}
$$

The agent enterprise ${ }_{i}$, s expected return from knowledge production is:

$V_{A_{i}}=m_{A_{i}} k q e_{C}{ }^{a} e_{A_{i}}{ }^{b}-\frac{1}{2} l e_{A_{i}}{ }^{2}$

In the function (4), $\frac{\mathbb{I} V_{C}}{\mathbb{I} e_{C}}=a m_{C} k q e_{C}{ }^{a-1} e_{A_{i}}{ }^{b}-l e_{C}$

In the function (5), $\frac{\mathbb{I} V_{A_{i}}}{\mathbb{I} e_{A_{i}}}=b m_{A_{i}} k q e_{C}{ }^{a} e_{A_{i}}{ }^{b-1}-l e_{A_{i}}$

$\quad \frac{\mathbb{I} V_{C}}{\mathbb{I} e_{C}}=0 \quad \frac{\mathbb{I} V_{A_{i}}}{\mathbb{I} e_{A_{i}}}=0$
Let, w
$e_{C}=\frac{k q}{l}\left(a m_{C}\right)^{\frac{1+a}{2}}\left(b m_{A_{i}}\right)^{\frac{b}{2}}$

work out solutions to the simultaneous equations, and we can get the optimum investment effort degree of the core enterprise as the knowledge investor:

The optimum investment effort degree of the agent enterprises is:

$$
e_{A_{i}}=\frac{k q}{l}\left(a m_{C}\right)^{\frac{a}{2}}\left(b m_{A_{i}}\right)^{\frac{1+b}{2}}
$$

From Eq. 8 and 9, we can know that the effort degree of the core enterprise is positively correlated with the number of the agent enterprises because the larger the number of the agent enterprises is, the knowledge cooperation coefficient will be higher, the total gain of the platform innovation ecosystem's 
cooperative innovation will be larger, and the partners of the platform innovation ecosystem will be more positive to take part in the cooperation. Besides, it is not hard to find that along with the increase of cost coefficient of the core enterprise and agent enterprises' knowledge investment, the enthusiasm of the partners to take part in knowledge production will reduce.

Put Eq. 8 and 9 into Eq. 3 and we can get:

$$
V_{B}=\frac{k^{2} q^{2}}{l}\left(1-m_{C}-k m_{A_{i}}\right)\left(a m_{C}\right)^{a}\left(b m_{A_{i}}\right)^{b}-g
$$

Derivate $m_{C}$ and $m_{A_{i}}$ from Eq. 10, let the derivatives be equal to zero, and work out solutions to the simultaneous equations:

$$
\begin{aligned}
& m_{C}=\frac{a}{2} \\
& m_{A_{i}}=\frac{b}{2 k}
\end{aligned}
$$

Because $^{m_{B}+m_{C}+k m_{A_{i}}=1}$ and $a+b=1$, we can get:

$m_{B}=\frac{1}{2}$

From Eq. 11 and 12, we can know the profit which the core enterprise and the agent enterprises can get is positively correlated with the influencing weight of their investment on knowledge production value. The larger the value that is generated from the knowledge production, the more profit they can be distributed. As for the core enterprise, the total distributed profit ratio is $m_{C}+m_{B}=\frac{a}{2}+\frac{1}{2}$, which is more than half of the value that the knowledge production brings, because the core plays the role of knowledge production manager and the role of knowledge investor and its position in the whole platform innovation ecosystem is very important.

Put Eq. 11 and 12 into Eq. 8 and 9, and we can get the optimum knowledge investment effort are as follows:

$$
\begin{aligned}
& e_{C}^{*}=\frac{(k q)^{\frac{1+a}{2}} a^{a} b^{b}}{2 l} \\
& e_{A_{i}}^{*}=\frac{(k q)^{\frac{a}{2}} a^{a} b^{(1+b)}}{2 l}
\end{aligned}
$$

From Eq. 14 and 15, we can know the knowledge investment effort is closely related to the influencing weight coefficient in the knowledge production function.

Put Eq. 11, 12, 13, 14 and 15 into Eq. 3, 4 and 5, we can get:

$$
\begin{aligned}
& V_{B}^{*}=\frac{(k q)^{(1+a)} a^{2 a} b^{2 b}}{4 l}-g \\
& V_{C}^{*}=\frac{(k q)^{1+a)} b^{2 b}(1+b)}{8 l} \\
& V_{A_{i}} *=\frac{(k q)^{a} a^{2 a}(1+a) b^{(1+2 b)}}{8 l}
\end{aligned}
$$

The total profit of the core enterprise is as follows:

$$
V_{B}^{*}+V_{C}^{*}=\frac{(k q)^{1+a)} b^{2 b}\left(a^{2 a}+1+b\right)}{8 l}-g
$$


From Eq. 19 we can know that the larger the number of the agent enterprises that take part in the platform innovation ecosystem is, the knowledge cooperation coefficient will be higher, and the total profit of the core enterprise will be higher. Besides, to make the core enterprise to be positive to engage in knowledge production and knowledge investment, the condition $V_{B}{ }^{*}+V_{C}{ }^{*}>0$, e.g. $g<\frac{(k q)^{1+a)} b^{2 b}\left(a^{2 a}+1+b\right)}{8 l}$

must be satisfied. This means that only when the management cost of the core enterprise is low to a certain degree the core enterprise will take part in the knowledge production and knowledge investment.

As for the agent enterprises, only when the condition $V_{A_{i}}{ }^{*}>0$ is satisfied, they will take part in knowledge investment. In Function (19), since $0<a, b<1$, the condition $V_{A_{i}}{ }^{*}>0$ is satisfied. This means it's profitable for the agent enterprises to take part in knowledge investment and knowledge sharing.

\section{Conclusions}

Supposing the core enterprise which plays both the role of the platform innovation ecosystem manager and the role of knowledge investment in the cooperative product development, the essay studies the profit distribution coefficient, knowledge investment effort and the profit from cooperative knowledge production of the core enterprise and the agent enterprises. The conclusions are as follows:

a. The profit distributed to the core enterprise and the agent enterprises of the platform innovation ecosystem is positively correlated with the impact weight of their knowledge investment on the knowledge production value, i.e. the higher the impact weight is, the more profit they may gain. As the same time, because of its leading position the core enterprise will get more than half of the total profit of the whole platform innovation ecosystem.

b. The larger the number of the agent enterprises in the platform innovation ecosystem is, the higher level of knowledge investment the core enterprise will make, and the larger the core enterprise's total gain will be. Therefore, as the knowledge manager of the whole platform innovation ecosystem, the core enterprise should try its best to abstract more agent enterprises to join in the platform innovation ecosystem.

c. Since the coordination degree of the core enterprise' and the agent enterprises' knowledge will also influence the total gain of the core enterprise, the core enterprise shall choose those agent enterprises which own high knowledge coordination degree as the members of the platform innovation ecosystem

\section{References}

[1] Annabelle Gawer, Michael A. Cusumano. How companies become platform leaders. MIT Sloan management review,2008,49(2):28-35.

[2] Baldwin, C. Y.,K. B. Clark.Design rules: The power of modularity[M].Cambridge, MA MIT Press, 2000.

[3] Schilling, M. A. Towards a general modular systems theory and its application to inter-firm product modularity. Academy of Management Review,2000,25(2): 312-334.

[4] Suarez, F. F.Battles for technological dominance: An integrated framework. Research Policy, 2004,33(2): 271-286.

[5] Murmann, J. P.,K. Frenken.Towards a systematic framework for research on dominant designs, technological innovations, and industrial change.Research Policy, 2006,35(7): 925-952. 
[6] Robert K. Perrons. The open kimono: how Intel balances trust and power to maintain platform leadership. Research Policy,2009,38(7): 1300-1312.

[7] Ron Adner,Rahul Kapoor. Value creation in innovation ecosystems: how the structure of technological interdependence affects firm performance in new technology generations. Strategic Management Journal,2010,31(3): 306-333.

[8] Satish Nambisan,Robert A. Baron. Entrepreneurship in innovation ecosystems: entrepreneurs' self-regulatory processes and their implications for new venture success.Entrepreneurship Theory and Practice,2012,36(5):32-76.

[9] Ceccagnoli,M., Forman, C., Huang, P., \&Wu, D.J.. Co-creation of value in a platform ecosystem: The case of enterprise software. MIS Quarterly, 2012,36(1),263-290.

[10] S Scholten, U Scholten. Platform-based innovation management: directing external innovational efforts in platform ecosystems . Journal of the Knowledge Economy,2012,2(3): 164-184.

[11]ZHANG Li-fei. Research on Operation Mechanism of High-tech Enterprise Innovation Ecosystem. Forum on Science and Technology in China, 2009(4): 57-61

[12]ZHANG Yun-sheng. Risk discoverym echanism of innovation ecosystem of hi-tech enterprise. Studies in Science of Science, 2009,27(6): 925-931 